\title{
ANÁLISE DOS EFEITOS DA CORROSÃO SOBRE A DUCTILIDADE DE ARMADURAS CORROÍDAS POR ENSAIOS ACELERADOS
}

\author{
CARLOS EDUARDO TINO. BALESTRA \\ Professor Doutor \\ Universidade Tecnológica Federal do Paraná \\ Paraná; Brasil \\ e-mail: carlosbalestra@utfpr.edu.br
}

\author{
FABIO ALEXANDRE. SPANHOL \\ Professor Doutor \\ Universidade Tecnológica Federal do Paraná \\ Paraná; Brasil \\ e-mail: faspanhol@utfpr.edu.br
}

\author{
JEFFERSON GUSTAVO. MARTINS \\ Professor Doutor \\ Universidade Tecnológica Federal do Paraná \\ Paraná; Brasil \\ e-mail: martins@utfpr.edu.br \\ GUSTAVO. SAVARIS \\ Professor Doutor \\ Universidade Tecnológica Federal do Paraná \\ Paraná; Brasil \\ e-mail: gsavaris@utfpr.edu.br
}

\section{RESUMO}

A corrosão das armaduras em estruturas de concreto é um dos principais mecanismos que leva a sua degradação. Tal fato é agravado quando tais estruturas estão presentes em ambiente marinho, o que reduz sua capacidade portante e, em casos extremos, pode levar a colapsos estruturais. Dada importância do tema, os efeitos da corrosão nas propriedades mecânicas de barras corroídas por métodos acelerados são analisados neste trabalho. Para tanto, 6 corpos de prova cilindricos ( $5 \mathrm{~cm}$ de diâmetro x $30 \mathrm{~cm}$ de comprimento) de concreto, armados cada um com uma barra com diâmetro de $12,5 \mathrm{~mm}$ e comprimento de $25 \mathrm{~cm}$ foram analisados. Os corpos foram parcialmente imersos em uma solução de $3,5 \%$ de $\mathrm{NaCl}$, sendo submetidos a procedimentos de corrosão acelerada através da impressão de uma corrente elétrica por 3 dias. Em seguida, as armaduras corroídas foram extraídas, decapadas através de uma solução de hexametileno tetramina e foram submetidas à tração. Outras seis barras de referência (barras não corroídas) com o mesmo diâmetro também foram ensaiados à tração. Os resultados mostraram que a corrosão das barras pode levar a uma redução da ductilidade das mesmas, reduzindo a deformação plástica das armaduras e a capacidade portante de uma estrutura a depender do grau de corrosão apresentado pelas armaduras.

Palavras-chave: Corrosão, Resistência à tração, Ductilidade.

\section{ABSTRACT}

Reinforcement corrosion in concrete structures is one of the main mechanisms that lead to its degradation. This fact is aggravated when these structures are present in marine environment, reducing their bearing capacity and, in extreme cases, may lead to structural collapses. Due to the importance of this issue, corrosion effects on the mechanical properties of corroded bars by accelerated methods are analyzed in this work. For this, six cylindrical concrete specimens $(5 \mathrm{~cm}$ in diameter $\mathrm{x} 30 \mathrm{~cm}$ in length) each reinforced with a $12.5 \mathrm{~mm}$ bar diameter with length of $25 \mathrm{~cm}$ were analyzed. The samples were partially immersed in a $3.5 \% \mathrm{NaCl}$ solution and subjected to accelerated corrosion procedures by printing an electric current for 3 days. Afterwards, the corroded reinforcement were extracted, cleaned with a solution of hexamethylene tetramine and subsequently subjected to tension test. Other six reference bars samples (non-corroded bars) with the same diameter were analyzed. The results showed that reinforcement corrosion leads to decrease bars ductility, reducing plastic strains of the bars and the structure bearing capacity depending on the corrosion degree presented by the reinforcement.

Keywords: Corrosion, Tensile strength, Ductility.

\section{INTRODUÇÃO}

Na construção civil, estruturas de concreto armado são amplamente utilizadas devido as suas características mecânicas e facilidade de execução. Entretanto, problemas relacionados à corrosão das armaduras têm se mostrado recorrentes, prejudicando a funcionalidade e segurança destas estruturas e, em casos extremos, podendo chegar a comprometer sua integridade estrutural (NEVILLE, 2016). 
Neste ponto, deve ser ressaltado que, inicialmente, o $\mathrm{pH}$ alcalino do concreto que reveste as armaduras se caracteriza como um meio protetor às estruturas frente à corrosão, através da formação de um filme passivante. No entanto, o ingresso de agentes agressivos do meio externo como dióxido de carbono (presente em ambiente urbano) e cloretos (presentes em ambiente marinho), ao atingir as armaduras, acabam criando condições para desencadear o processo corrosivo. Tal processo leva à formação de produtos de corrosão de caráter expansivo que promovem um processo de degradação contínua da estrutura (GENTIL, 2003; MEHTA e MONTEIRO, 2008).

Do processo corrosivo, três são os principais efeitos promovidos pela corrosão das armaduras sobre as estruturas de concreto. O primeiro trata da redução da seção transversal da armadura, reduzindo a área de aço destinada a resistir esforços de tração nas estruturas de concreto armado, afetando sua capacidade portante. O segundo está relacionado à formação de produtos de corrosão expansivos que, à medida que se formam, exercem tensões radiais ao eixo das armaduras que não são suportadas pelo concreto. Tal processo leva à formação de fissuras e ao lascamento da camada de cobrimento e potencializa a entrada de agentes agressivos promotores do processo corrosivo. Por fim, o terceiro efeito está relacionado à perda de aderência entre a armadura e o concreto, o que prejudica a transferência de esforços entre estes elementos que compõem a estrutura (MEHTA e MONTEIRO, 2008; BALESTRA, 2013).

Neste ponto, Balestra et al. (2016) analisaram os efeitos da corrosão nas propriedades mecânicas de armaduras que permaneceram sob processo de corrosão natural por quase 50 anos. Os autores verificaram que os efeitos da corrosão são significativos, sobretudo na ductilidade das barras (capacidade de deformação das barras anterior ao rompimento). Os autores verificaram reduções no alongamento final das barras, mesmo quando estas apresentavam pequeno grau de corrosão. Os autores também observaram que, mesmo barras que apresentaram grau de corrosão de 5 a $10 \%$, apresentaram valores de alongamento final inferiores ao limite prescrito pela NBR 7480 (ABNT:2007) que é igual a $8 \%$. Os autores creditam este fato à presença de pites nas barras, visto que mesmo barras com pequena variação de massa podem apresentar pites profundos e, consequentemente, significativas reduções nas propriedades mecânicas das armaduras.

Apostolopoulos e Papadakis (2007) analisaram as propriedades mecânicas de barras corroídas por períodos de 10 a 60 dias utilizando uma câmara de névoa salina. Os autores determinaram o grau de corrosão das barras por meio da variação de massa e, posteriormente, submeteram as barras ao ensaio de tração. Os autores observaram que o maior decréscimo entre as propriedades mecânicas foi verificado na ductilidade das barras analisadas. Além disso, quanto maior o período de exposição à névoa salina, maior foi o grau de corrosão obtido e, consequentemente, menor foi o alongamento final obtido nas barras.

Almusallam (2001) promoveu a corrosão de armaduras por meio de procedimentos acelerados. Para tanto, corpos de prova prismáticos reforçados com barras com diâmetros de 6 e $12 \mathrm{~mm}$ foram parcialmente imersos em uma solução de 3,5\% de $\mathrm{NaCl}$ e uma corrente foi impressa para acelerar o processo corrosivo. Após o período de aceleração da corrosão, as barras foram retiradas dos corpos de prova, submetidas a processo de decapagem química (para remoção de produtos de corrosão aderidos às barras) e ensaiadas à tração. Os autores observaram que barras com grau de corrosão superior a 12,6\% podem apresentar fratura frágil, isto é, romper de maneira repentina, sem apreciável deformação.

Acosta, Gutierrez e Guillén (2006) apresentam uma investigação experimental referente à capacidade de carga de vigas sujeitas à flexão que apresentam corrosão de suas armaduras. Neste estudo, doze vigas de concreto armado foram executadas com adição intencional de cloretos e uma corrente foi impressa nas barras de armaduras para acelerar o processo corrosivo por períodos de 40, 80 ou 200 dias. Posteriormente as vigas foram submetidas a um ensaio de flexão em 3 pontos. Os resultados demonstraram que, quanto maior o grau de corrosão apresentado pelas armaduras, menores foram as capacidades de suporte de carga e as deformações na ruptura das vigas, demonstrando que a corrosão não apenas afeta a resistência das armaduras corroídas, mas também da estrutura quando submetida à carregamentos.

Mediante a problemática exposta, o presente trabalho tem como objetivo apresentar os efeitos da corrosão sobre a ductilidade de armaduras. Para tanto, barras de aço com diâmetro de 12,5 mm foram inseridas em corpos de prova de concreto e submetidas a processos de corrosão acelerada em laboratório. Em seguida, as armaduras foram extraídas, tiveram seu grau de corrosão determinado e foram, por fim, ensaiadas à tração direta, sendo o alongamento final das barras analisado e correlacionado ao grau de corrosão apresentado. 


\section{PROGRAMA EXPERIMENTAL}

Neste estudo foram utilizadas 12 barras de aço CA-50 com diâmetro igual a 12,5 mm e comprimento igual a $25 \mathrm{~cm}$, divididas em dois grupos, sendo que o primeiro grupo (grupo A - 6 barras) foi utilizado como referência (não submetidas à corrosão acelerada). Já o segundo grupo (grupo B - 6 barras) compreende as barras que foram submetidas ao processo de corrosão acelerada em laboratório. Para tanto, seis corpos de prova cilíndricos de concreto com diâmetro de $5 \mathrm{~cm}$ e comprimento de $30 \mathrm{~cm}$ contendo uma barra de aço em seu interior foram moldados. A justificativa para estas dimensões dos corpos de prova está relacionada a produzir corpos de prova com uma camada de cobrimento próxima a 2,0 cm, valor este que era recomendado pela versão da norma NBR 6118 vigente até 2003 (ABNT: 2003) para a execução de estruturas de concreto armado.

A respeito das características do concreto (dosado segundo o método da Associação Brasileira de Cimento Portland), o traço de concreto em massa $(\mathrm{kg} / \mathrm{kg})$ utilizado neste trabalho foi 1: 1,49: 2,06: 0,50 (Cimento : Areia: Pedrisco: Água), tendo sido utilizado cimento CP II F-32, agregado miúdo proveniente do leito do Rio Paraná e pedrisco de origem basáltica. Os materiais foram misturados com uso de uma betoneira, sendo realizados o ensaio de abatimento do tronco de cone, conforme a NBR NM 67 (ABNT:1998) e a moldagem de 6 corpos de concreto cilíndricos com $10 \mathrm{~cm}$ diâmetro, conforme NBR 5738 (ABNT :2018a), para a realização de ensaios de compressão aos 28 dias, conforme a NBR 5739 (ANBT: 2018b). O valor de abatimento obtido foi igual a $92 \mathrm{~mm}$ e a resistência à compressão média dos corpos de prova foi igual a $32 \mathrm{MPa}$.

Seis corpos de prova de concreto com uma barra foram executados para realizar os ensaios de aceleração da corrosão. Neste caso, em primeiro lugar, a massa e comprimento das barras antes do processo de aceleração da corrosão foram determinados e, posteriormente fios elétricos flexíveis com seção igual a 2,5 mm foram fixos a uma das extremidades das barras com o objetivo de conectá-los a fonte para impressão de uma corrente elétrica. Além disso, um comprimento igual a $70 \mathrm{~mm}$ a partir de cada extremo das barras foi revestido com material isolante visando preservar esta região para fixação das barras nas garras do equipamento de tração.

Após estes procedimentos, as barras foram posicionadas no centro dos moldes de PVC dos corpos de prova de concreto, visando garantir uma camada de cobrimento uniforme, sendo, posteriormente, preenchido com concreto e adensado com 12 golpes utilizando um martelo de borracha, distribuídos nas laterais do molde. Após 24 horas, estes corpos de prova foram desmoldados e encaminhados para cura submersa a uma temperatura de $23 \pm 2^{\circ} \mathrm{C}$ por 28 dias, com o objetivo de garantir a formação de um filme passivante para revestir a armadura no interior do concreto.

Decorrido este período de cura, os corpos de prova foram secos em estufa por 24 horas a $105^{\circ} \mathrm{C}$ e, posteriormente, foram parcialmente imersos em uma solução de 3,5\% de $\mathrm{NaCl}$ (concentração próxima à observada na água do mar) por 14 dias, visando a penetração de cloretos presentes na solução através da rede de poros do concreto por meio de mecanismos de absorção capilar. Após este período, os corpos de prova foram conectados a uma fonte e a uma barra de cobre, onde uma corrente igual a 0,84A foi impressa por 3 dias visando acelerar o processo de corrosão das barras nos corpos de prova de concreto e observando respeitar a máxima tensão da fonte. A Figura 1 apresenta uma vista do processo de aceleração da corrosão das barras junto aos corpos de prova.

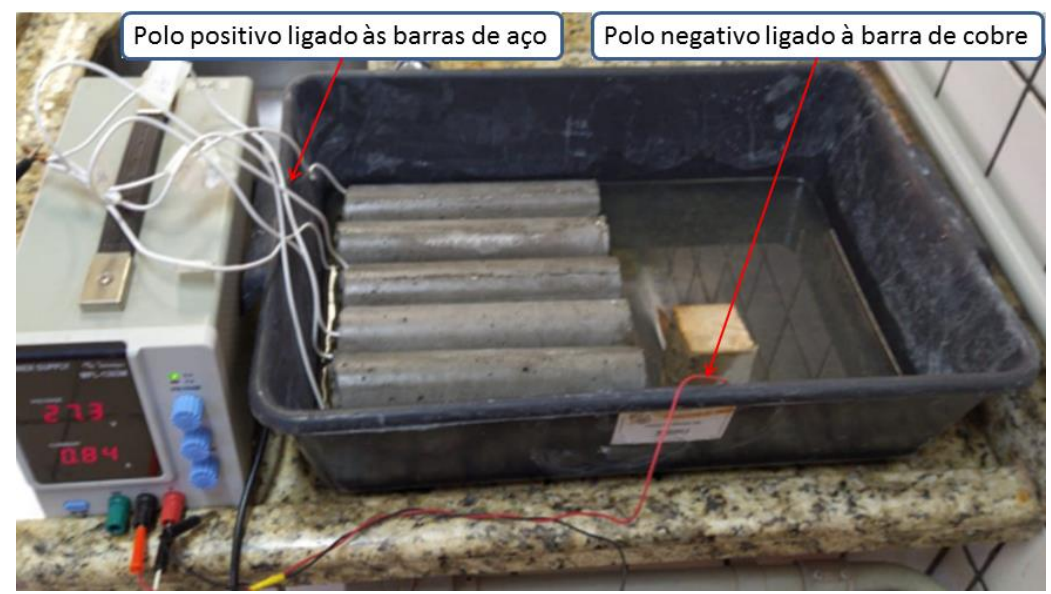

Figura 1: Processo de aceleração da corrosão. 
Posteriormente ao processo de aceleração da corrosão, as barras foram extraídas dos corpos de prova e submetidas a um processo de decapagem química utilizando uma solução de hexametileno tetramina, conforme prescreve a norma ASTM G1: 2003, com o objetivo de retirar os produtos de corrosão aderidos à superfície das barras. Na sequência, a massa corroída das barras foi registrada para determinação do grau de corrosão das mesmas e, posteriormente, foram ensaiadas à tração em uma máquina Universal EMIC DL 30000, sendo o alongamento final determinado após a ruptura das barras com uso de paquímetros. Vale ressaltar ainda que as barras do grupo A também foram submetidas ao ensaio de tração, sendo seu alongamento final utilizado como referência. Neste caso, a NBR 7480: 2007 prescreve que uma barra CA-50 deve apresentar no mínimo um alongamento final igual a $8 \%$.

\section{RESULTADOS E DISCUSSÃO}

A Figura 2 apresenta os valores de alongamento observados nas barras pertencentes ao grupo A (corpos de prova 1 a 6 ) e ao grupo B (corpos de prova 7 a 12). Além disso, a Figura 3 apresenta a relação existente entre o grau de corrosão e o alongamento final, observado nas barras dos grupos A e B.

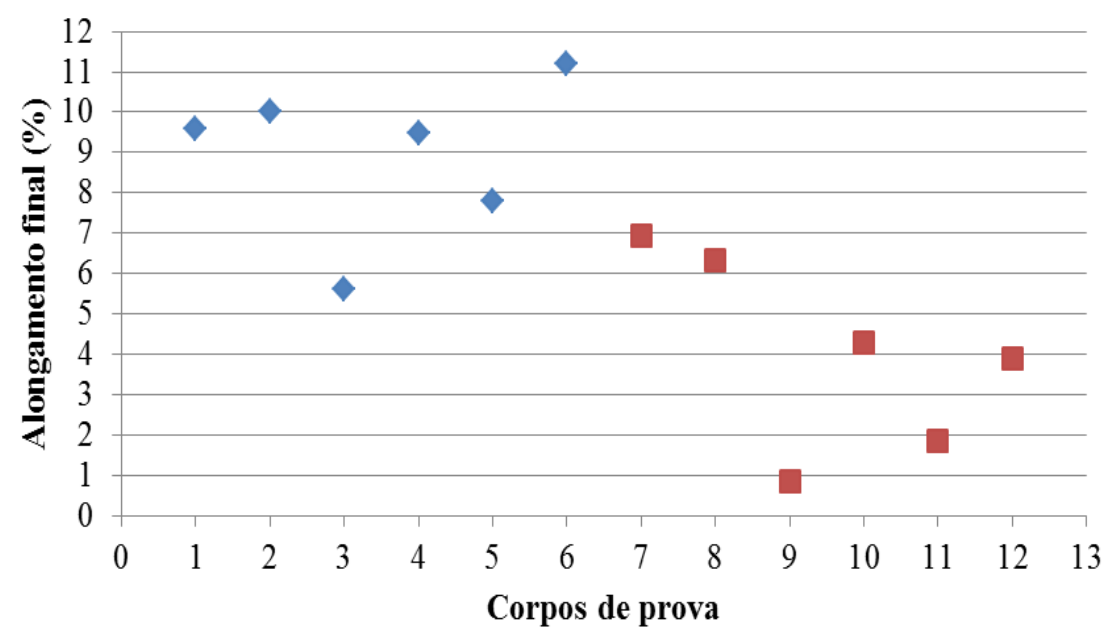

$\bullet$ Barras Grupo A $\quad$ Barras Grupo B

Figura 2: Alongamento final das barras dos grupos A e B

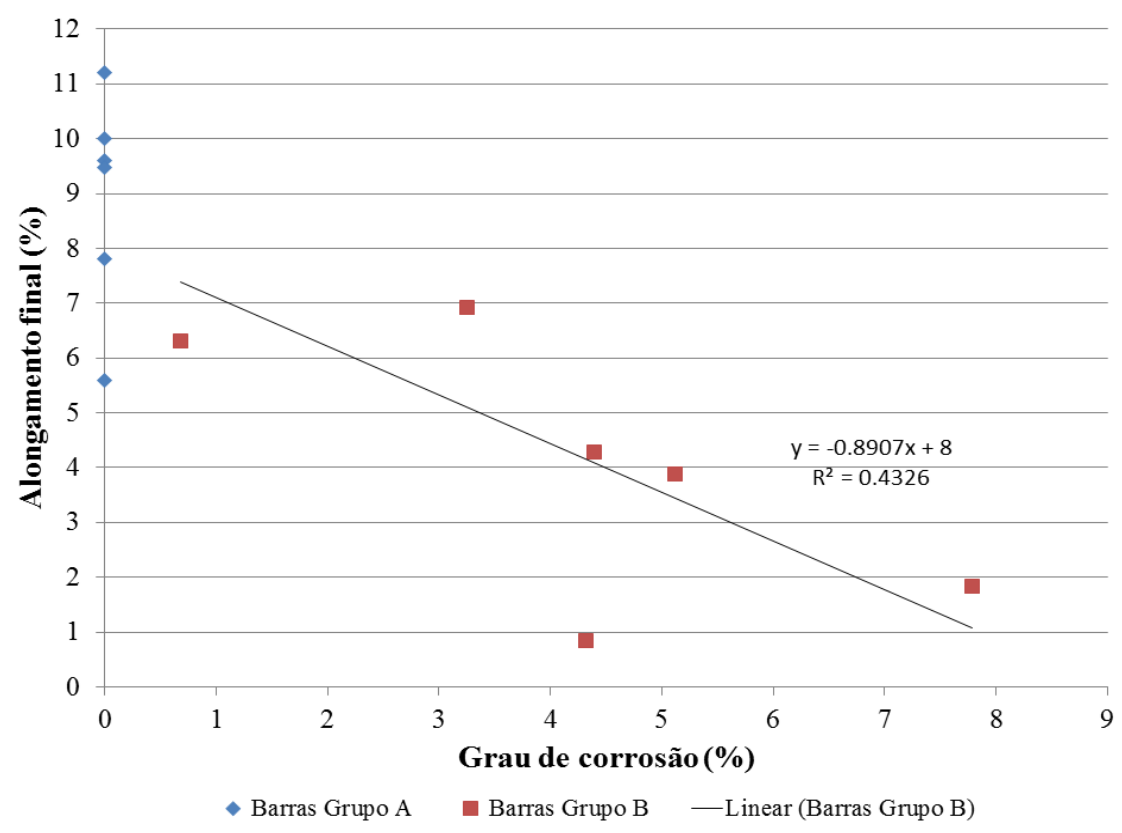

Figura 3: Relação entre o grau de corrosão e o alongamento final das barras corroídas 
Na Figura 2 é possível observar que, com a exceção de uma das barras, a maioria das barras pertencentes ao grupo A atenderam ao valor mínimo de alongamento final prescrito pela norma NBR 7480: 2007 (8\% para barras CA-50). Além disso, estas apresentaram valores de alongamento final superiores aos valores apresentados pelas barras corroídas (grupo B), para as quais houve variações superiores a 10\%, demonstrando que a ductilidade das armaduras é afetada pela corrosão. Além disso, é possível observar na Figura 3 que barras de aço que apresentaram grau de corrosão a partir de $3 \%$ não atenderam aos parâmetros mínimos da norma. Isto indica que, a partir destes valores de graus de corrosão, barras de aço que reforçam estruturas de concreto armado podem não apresentar deformações mínimas prescritas por norma quando submetidas a carregamentos.

Neste caso em específico, a corrosão observada visualmente nas barras foi a corrosão por pites devido à ação dos cloretos presentes na solução de $\mathrm{NaCl}$, com pontos bem definidos na superfície das barras que se aprofundaram à medida que o processo corrosivo progrediu. Tal tipo de corrosão pode caracterizar pequena variação de massa, mas com danos significativos às propriedades mecânicas das armaduras, corroborando com o estudo de Balestra et al. (2016).

Ainda observando a Figura 3 é possível notar uma variação entre os graus de corrosão observados nas barras analisadas, com variações entre 0,68 e 7,78\% mostrando a aleatoriedade relativa ao processo corrosivo desenvolvido. De qualquer maneira é possível observar que, à medida que o grau de corrosão se intensifica, menor o alongamento observado nas barras de aço devido aos efeitos da corrosão. Neste ponto, é possível propor uma equação linear (com $\mathrm{R}^{2}$ igual a 0,4326$)$ para representar a redução na ductilidade das armaduras (Equação 1), tendo em vista que há uma aleatoriedade quanto ao grau de corrosão sofrido pelas armaduras. Vale ressaltar que esta Equação foi ajustada visando representar fisicamente os efeitos da corrosão sobre a ductilidade das barras, uma vez que barras que apresentam-se isentas de corrosão devem apresentar o valor mínimo de alongamento final definido como igual a $8 \%$.

Alongamento Final $(\%)=-0,8907 \cdot($ grau de corrosão, $\%)+8,000$

Outro ponto observado trata do modo de fratura das barras. Observou-se que algumas barras corroídas apresentaram uma seção de ruptura com uma ângulo próximo a $45^{\circ}$, ao passo que houve a formação de um cone de ruptura nas barras isentas de corrosão. A Figura 4 apresenta uma imagem comparando uma barra isenta de corrosão e uma barra corroída (Com grau de corrosão da ordem de 4,5\%) após a ruptura no ensaio de tração, por meio da qual também é possível observar a variação no alongamento final das barras, que nos resultados dos ensaios chegou a valores da ordem de $10 \%$ mesmo considerando barras com grau de corrosão da ordem de 4,5\%.

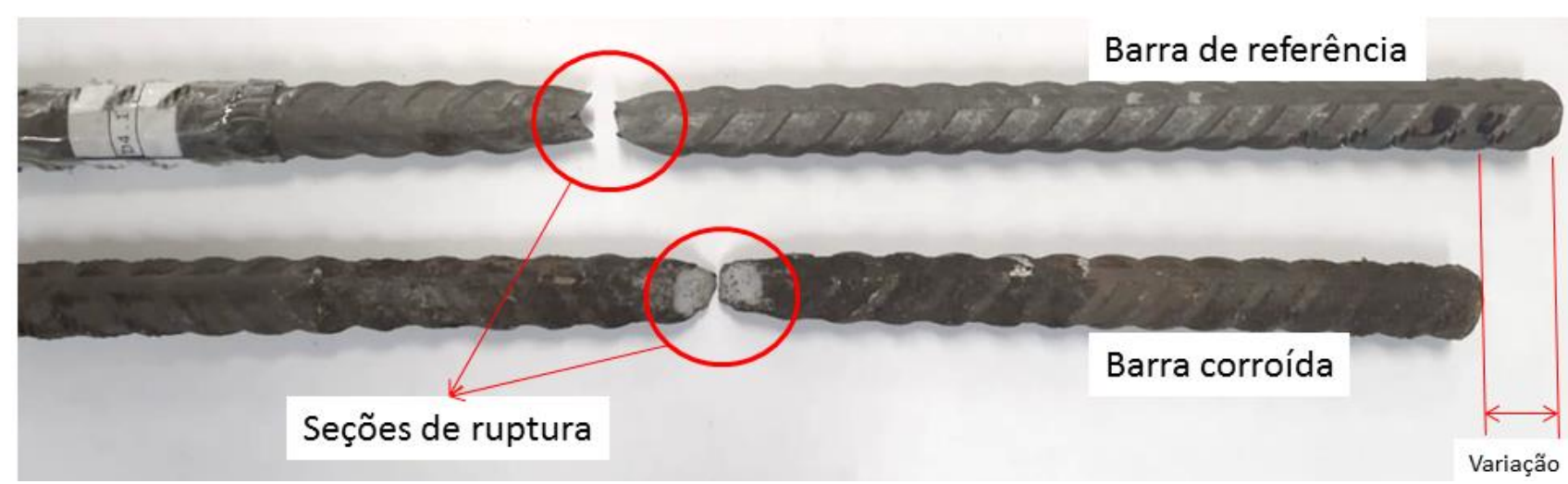

Figura 4: Seção de ruptura das barras e variação no alongamento final.

Tal comportamento demonstra que, além da redução no alongamento final, a forma de ruptura das barras é alterada devido aos efeitos da corrosão. Neste caso, observando a forma de ruptura, é possível concluir que a atuação de forças de cisalhamento entre as seções sucessivas das barras corroídas foi o sistema preponderante que levou à ruptura das barras. Além disso, deve-se ressaltar que a corrosão produz variações de excentricidade entre as seções transversais sucessivas de barras corroídas. Desta forma, considerando que a atuação de esforços de tração se dá ao longo do eixo das armaduras, quando estas barras apresentam corrosão e excentricidades entre as seções transversais, o cisalhamento é 
de fato o mecanismo preponderante que leva à ruptura das armaduras, justificando o comportamento observado na ruptura de barras corroídas.

\section{CONCLUSÕES}

O presente trabalho apresenta os efeitos da corrosão sobre a ductilidade de armaduras submetidas a processo de corrosão acelerada em laboratório por três dias. As principais conclusões do trabalho são:

- A corrrosão afeta a ductilidade das armaduras, sendo que, mesmo quando houver um pequeno grau de corrosão, haverá redução de alongamento final das barras. Além disso, na fratura observou-se que o cisalhamento foi o mecanismo preponderante.

- A corrosão por pites foi o principal tipo de corrosão verificado nas barras devido à ação dos cloretos presentes na solução de $\mathrm{NaCl}$, tendo sido verificados variados graus de corrosão.

- Barras de aço com grau de corrosão acima de $3 \%$ podem não atender aos parâmetros mínimos de alongamentos prescritos na norma brasileira NBR 7480, assim estruturas de concreto degradadas podem ter sua capacidade portante prejudicada.

- Uma equação linear foi proposta para representar a relação existente entre o grau de corrosão e o decréscimo no alongamento final de barras corroídas quando submetidas à tração, considerando que barras isentas de corrosão devem apresentar um valor mínimo de alongamento igual a $8 \%$ segundo as prescrições normativas vigentes para aço CA-50.

\section{AGRADECIMENTOS}

Os autores agradecem a Universidade Tecnológica Federal do Paraná campus Toledo e ao Grupo de Estudos em Materiais e Estruturas (GPMAES) pelo apoio à pesquisa.

\section{REFERÊNCIAS}

ACOSTA, A.A.T.; GUTIERREZ, S.N.; GUILLÉN J.T. Residual flexure capacity of corroded reinforced concrete beams. Engineering Structures, v.29, p.1145-1152, 2006.

ALMUSALLAN, A.A. Effect of degree of corrosion on the properties of reinforcing. Construction and Building Materials, v.15, p. 361-368, 2001.

APOSTOLOPOULOS, C.A; PAPADAKIS, V.G. Consequences of steel corrosion on the ductility properties of reinforcement bar. Construction and Building Materials, v.22, p. 2316-2324, 2007.

ASSOCIAÇÃO BRASILEIRA DE NORMAS TÉCNICAS. NBR NM 67: Concreto - Determinação da consistência pelo abatimento do tronco de cone. Rio de Janeiro, 1998.

ASSOCIAÇÃO BRASILEIRA DE NORMAS TÉCNICAS. NBR 5738: Concreto - Procedimento para moldagem e cura de corpos de prova. Rio de Janeiro, 2018a.

ASSOCIAÇÃO BRASILEIRA DE NORMAS TÉCNICAS. NBR 5739: Concreto - Ensaio de compressão de corposde-prova cilíndricos. Rio de Janeiro, 2018b.

ASSOCIAÇÃO BRASILEIRA DE NORMAS TÉCNICAS. NBR 6118: Projeto de estruturas de concreto Procedimento. Rio de Janeiro, 2003.

ASSOCIAÇÃO BRASILEIRA DE NORMAS TÉCNICAS. NBR 7480: Aço destinado a armaduras para estruturas de concreto armado - Especificações. Rio de Janeiro, 2007. 


\section{CBPAT 2020 \\ CONGRESSO BRASILEIRO DE PATOLOGIA DAS CONSTRUÇÕES \\ DE 15 A 17 DE ABRIL | FORTALEZA - CE \\ ISBN 978-65-86819-05-2}

BALESTRA, C.E.T. Influência do Grau de Corrosão na Resistência à Tração de Armaduras - Estudo de Caso das Antigas Fundações da Nova Ala Zero do ITA. 2013, 162p, Dissertação de Mestrado em Infraestrutura Aeronáutica. Instituto Tecnológico de Aeronáutica - ITA, Área de Infraestrutura Aeroportuária, São José dos Campos, SP, Brasil, 2013.

BALESTRA, C.E.T; LIMA, M.G.; SILVA, A.R.; MEDEIROS-JUNIOR, R.A. Corrosion degree effect on nominal and effective strengths of naturally corroded reinforcement. Journal of Materials in Civil Engineering, 28(10) p. 19, 2016.

GENTIL, V. Corrosão. $3^{\circ}$ Edição, Rio de Janeiro, LTC - Livros Técnicos e Científicos, 1996

MEHTA, P.K.; MONTEIRO, P.J.M. Concreto - microestrutura, propriedades e materiais. . $1^{\circ}$ edição em português traduzida da $3^{\circ}$ edição em inglês, São Paulo, Editora IBRACON, 2008.

NEVILLE, A. M. Propriedades do concreto. 5. ed. Porto Alegre: Bookman, 2016. 